\title{
The widening of structures over the Orange river on national route 12 section 9 near Hopetown, the Northern Cape.
}

\author{
Tiago Massingue ${ }^{1}$, and Chris Lourens ${ }^{2}$ \\ 1 The South African National Roads Agency SOC Ltd, Cape Town, South Africa \\ ${ }^{2}$ BVi Consulting Engineers, Structural Service Group, Cape Town, South Africa
}

\begin{abstract}
The South African National Roads SOC Agency (SANRAL) identified two bridges on the N12, section 9 to be widened and improved. The bridges were to be repaired of their existing structural defects and widened to allow safer passage of traffic and pedestrians along the route. Repairs to concrete, replacement of existing structural elements and retrofitting of improved elements were undertaken simultaneously to bring the bridges up to specification and safety standards. Through this effort, the bridges durability and lifespans were greatly improved and prolonged. Further substantial benefits were injected into the local environment and community through job creation and education with the local population of the area.
\end{abstract}

\section{Introduction}

As part of the Bridge Management System (BMS), the South African National Roads SOC Agency (SANRAL) identified the need to widen and improve two bridges. The bridges cross the Orange River and its tributaries along the N12, section 9, between Kimberly and Hope town in the Northern Cape. The section of road forms part of a major transit route linking Kimberly and the surrounding towns in the Northern Cape to Cape Town and the rest of the Western Cape. A heavy thoroughfare for large vehicles transporting a variety of materials, the route is a vital link in terms of infrastructure and an economic lifeline for the cities and towns it connects.

\section{Background}

The widening of the two structures, namely B2482 and B2483, forms part of an improvement project aimed at increasing the capacity of the existing route section as well as improving safety for roads users and pedestrians. The ongoing maintenance and rehabilitation required for these structures and the adjacent carriageways adds to the overall upgrading of multiple portions along the N12 route that was currently being completed. Additionally, the repair and upgrade work serves to extend the lifespan of the structures and maintain the important route for further decades to come.

The Orange River Bridge, B2482, was built in 1985 and is generally in a good condition. The overall length of the bridge is $312 \mathrm{~m}$ and comprised of 12 simply supported decks with spans of $26 \mathrm{~m}$ each. All decks were constructed from seven pre-cast post-tensioned reinforced concrete Ibeams with an in-situ, composite, reinforced concrete top slab. The carriageway, at $7.4 \mathrm{~m}$ wide, included a single carriageway along with narrow sidewalks and a concrete post and rail parapet on either side.

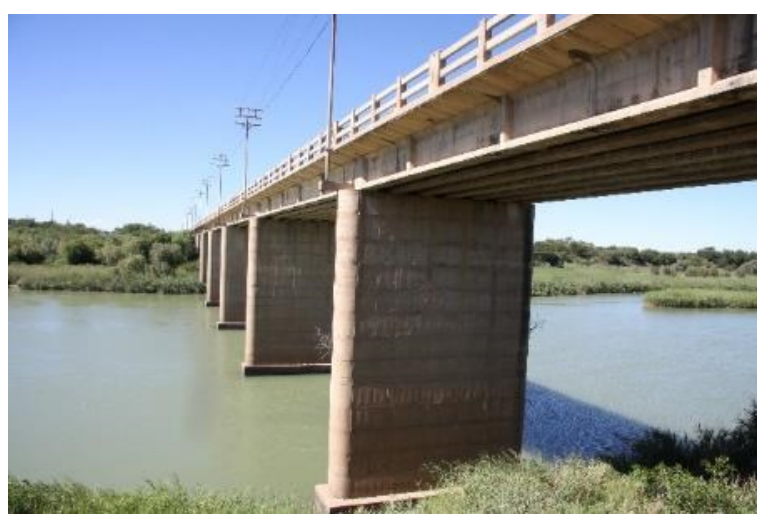

Fig. 1. Bridge 2482

The shorter bridge, B2483, was built in 1958 and is too in a satisfactory condition. The overall length of the bridge deck is $30 \mathrm{~m}$ and is comprised of $6 \times 5 \mathrm{~m}$ simply supported in-situ reinforced concrete slabs. The carriageway held the same $7.4 \mathrm{~m}$ wide single carriageway as the B2482 and included narrow pedestrian walkways on either side of the structure.

While the smaller bridge had little to no water running through it, B2482 spanned the large Orange River and subsequently always had moving water present. High abutments fill and the high volume river flow made the upgrading of the structure challenging, both in terms of access to the works and the impact on the surrounding environment. 


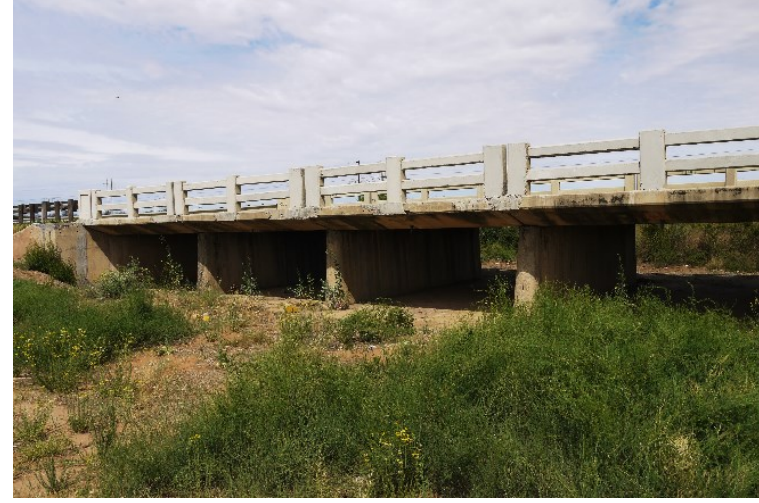

Fig. 2. Bridge 2483

Considerations were made in the early concept phase of the design to incorporate widening on both sides of the structures. This would have incurred a large cost and presented a prolonged construction approach which would greatly disturb the route. Safety and access to the structure also dictated that restrictions would have to be made in order to ensure that no adverse risks were taken in the widening. Thus the single side widening option was later adopted due to feasibility, safety, and practical standpoints and allowed the focus to be placed on ensuring the new structure met all the correct standards.

\section{Structural Issues}

While both structures along the route were functioning as designed and were not highly compromised structurally, the bridges, after 60 years of use, had safety issues and structural problems that eventually could lead to a more drastic failure.

A full repair from foundation to parapet would be undertaken to ensure that the structures would be safe and structurally sound for the foreseeable future. Creating cosmetically safer, more aesthetic structures would also serve to enhance the perception of the bridges as complete and well-maintained pieces of infrastructure.

\section{Substructure}

The substructure on both bridges had been exposed to various environmental conditions during the structure's lifespan and this was evident in the appearance.

\section{Foundations}

The foundations for B2482, mostly visible during lower flows, were in good condition. Further underwater survey work reinforced this evaluation and thus these elements required little to no rehabilitation work.

\section{Abutments}

The abutments of Bridge 2482 had experienced some nominal erosion and had settled in the approaches. The bearing seats had advanced cracks that seemed to have propagated from around the bearing plates. Additionally, localised spalling on the abutments straight return walls had occurred but had not compromised the supports in any way.

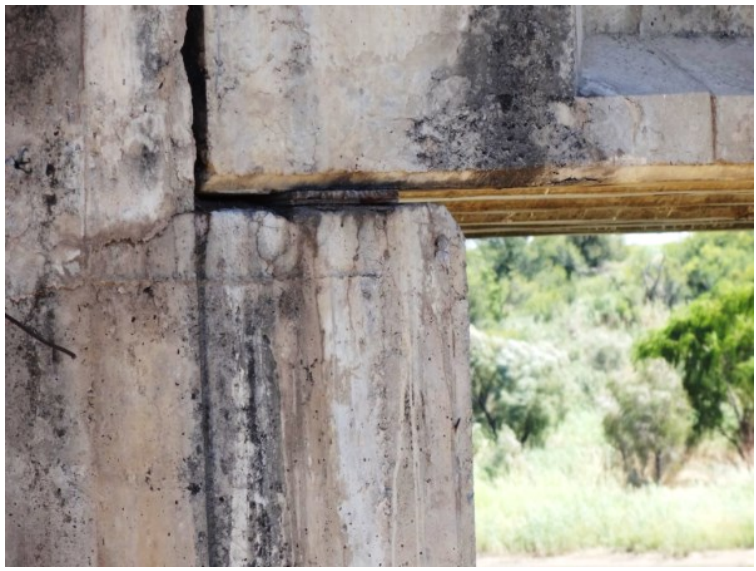

Fig. 3. Abutment condition

\section{Piers}

Leaching of water through the expansion gaps in the deck had created limescale build up and multiple defects across the face of the pier. This contributed to spalling and honeycombing effects that were present near the supports and at other areas in the face of the piers.

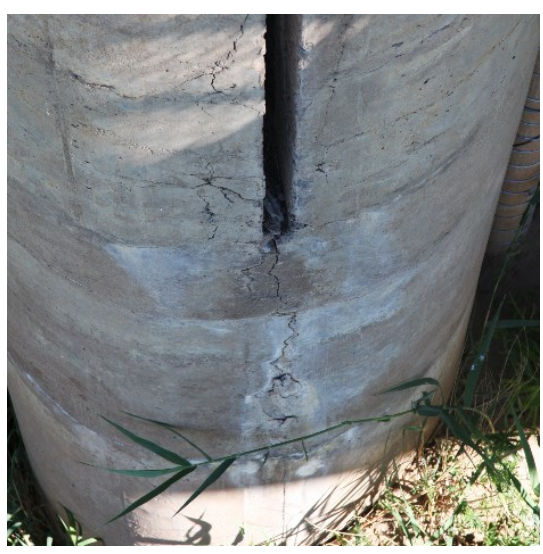

Fig. 4. Cracks at pier split position

Predominately concrete loss and subsequent cover to the reinforcement created spalling which in certain areas exposed the steel and lead to corrosion. This would require full removal of the corroded section and repair to reinstate cover. Honeycombing was prevalent near the beam support at the top of the piers.

The upper half of the piers, which comprised a split section to accommodate movement on B2482, was susceptible to a number of issues. Water ingress and flexure, from loading, created cracks where the solid pier section began. This was further affected by vegetation build up and spalling occurring on the edges. Blocked seals in line with the expansion joints in the split pier section prevented correct articulation of the two pier splits. 


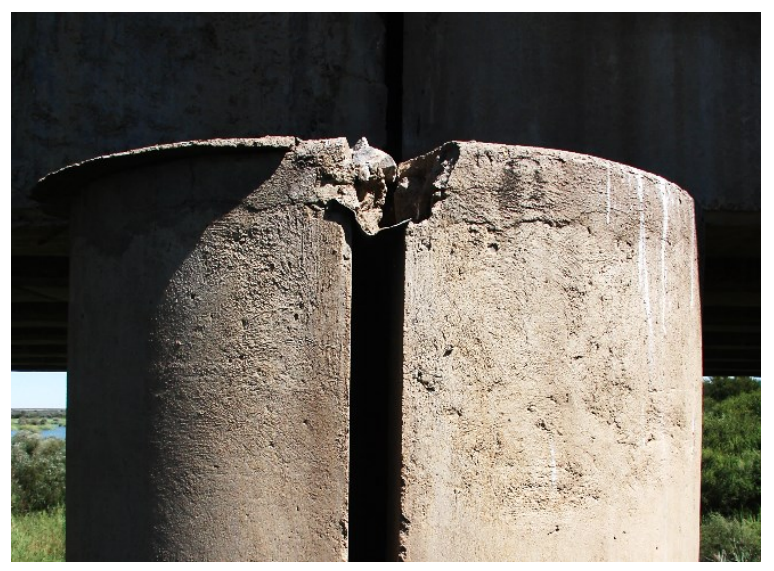

Fig. 5. Top of pier damage

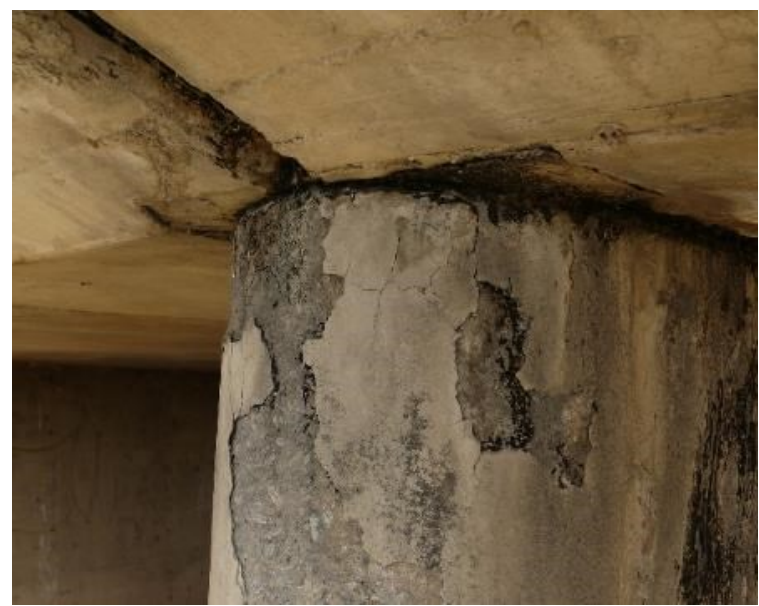

Fig. 6. B2483 pier delamination

On B2483, the solid abutment and piers had delamination near the tops as well as minor amounts of spalling and cracking around the pier deck interface. Most of the defects here were surface phenomenon and required a simple application of a protective cementitious compound. Previous poorly executed repair work was additionally removed and corrected in a neat and effective manner

\section{Superstructure}

\section{Beams}

The precast, pre-stressed beams that were installed on B2482 had various levels of honeycombing and spalling occurring from lack of adequate concrete vibration. It was clear to see, from the high occurrence of this particular issue, difficulty was experienced in obtaining the right compaction around the tension ducts when the bridges were constructed. Although, poor quality control or high densities of reinforcement could have also been blamed for the problem.

Further, the risk to the steel at these sections on the underside of the beams required they be correctly treated and repaired. Deviator plates had become exposed on the underside of the beams and poor fitting had led to considerable spalling occurring around these elements where concrete fines had leaked out. The tendons and reinforcement in these sections were not exposed and the spalled concrete would be repaired to specification.

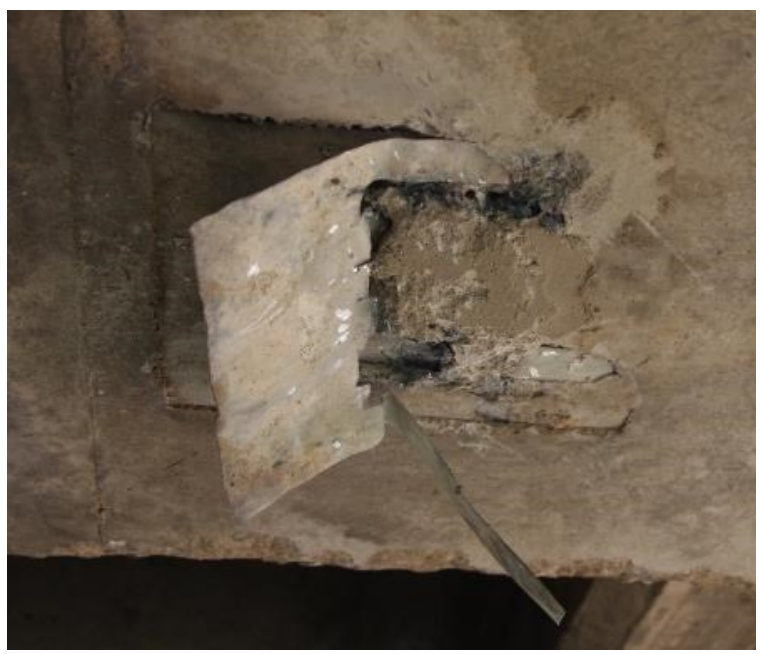

Fig. 7. Detached deviator plate cover

\section{Deck}

The deck condition on both bridges had a combination of structural issues as well as cosmetic problems that added to the overall levels of degradation of the structure. The underside of the cantilevered walkway in certain places had spalled and broken off with steel being left exposed to the elements. The drainage and expansion gap systems had not worked correctly and resulted in staining of the outside beams as well as a build-up of asphalt in the expansion gaps. This would have prevented free expansion of the simply supported deck and caused further cracking to occur.

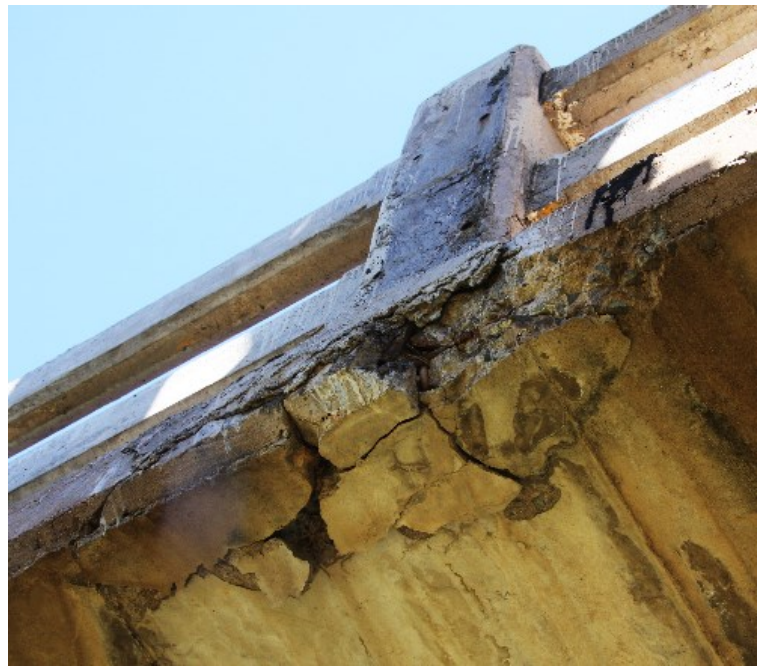

Fig. 8. Spalled cantilever deck edge

\section{Parapet}

The parapet in one section has completely failed, clearly from impact damage and had been left to hang by just the reinforcement. A temporary guardrail had been bolted 
across this section. Various other positions on B2482 had damaged parapets and these would eventually be completely removed and replaced.

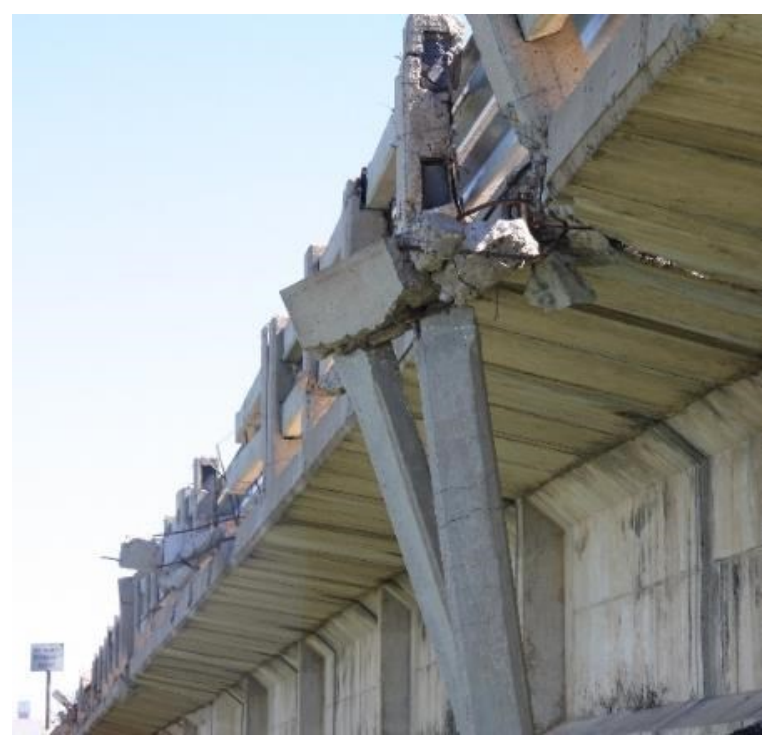

Fig. 9. Damaged parapet

\section{Structural Repair and Rehabilitation}

The repair systems on the project could be broadly grouped into three types based on the problem, risk to the structure at large, safety and ensuring structure longevity: Replace - Elements that had failed, posed a high safety risk and compromised the purpose of the structure.

Structural Repair - Elements that were affecting the structural integrity of the bridges and required appropriate structural repairs. These elements could not be completely replaced.

Protective Repair - Elements that were not of structural significance but were exposed or beginning to pose a risk, contributing to aesthetically displeasing sections of the structure. These would have extended the longevity of the structure.

\section{Replacements}

Certain elements were evaluated and found that repairing would have led to extremely costly and time-consuming construction. The older elements would have further been compromised as they were constructed as part of past systems and quality and safety could not be verified.

One such element was the parapets and pedestrian handrails which were completely demolished, removed and replaced with current SANRAL specification "F" shape barriers and precast handrails for the pedestrian walkway. This upgrade to the bridge and carriageway improved the overall safety and quality of barricades as well as the overall aesthetic, bringing the structure into the modern design of bridges around the country.

Another important element, structurally, that had to be replaced was the bridge joints. These were removed and cleaned out, with new waterproof asphaltic plugs installed.

\section{Structural Repairs}

The deck while being demolished on the downstream side to accommodate the retrofitting of new beams and widened roadway was structurally repaired in dilapidated areas. Bridge joints and expansion gaps were demolished and refitted with better, modern joint systems for managing movement and stormwater while other deck sections that were spalling or honeycombing were stripped, reinforcement treated and reinstated to their previous structural integrity.

Sika and their extensive product line played a large role in the different types of repairs required and allowed for a variety of problems to be solved. From small sections of crack repair and cover to larger, deeper sections where reinforcement needed to be completely exposed and concrete replaced to ensure good cover and protection.

\section{Protective Repairs}

Protective coatings were applied to existing sections of the bridge to further increase longevity of the structure. While these applications were usually only surface coats the added resistance to water ingress and cracking would allow the existing half of the structure to meet the new structure's durability and lifespan specifications.

These coatings were additionally blended and colour matched to ensure that, cosmetically, the two halves of the structure were more similar in colouring.

\section{Retrofitting of Widened Bridge}

In conjunction with the repairs and replacements completed on the old structures, a complete widened addition was made to both bridges following precisely the same dimensions and structural arrangement, albeit with improved strength and design characteristics.

On B2482 the full length of $312 \mathrm{~m}$ was widened by constructing new rock footing foundations and piers, averaging $15 \mathrm{~m}$ in height, of the same existing bridge dimension. Five, $25 \mathrm{~m}$ long, 26 ton, pre-stressed, precast beams were then craned into position for all 12 spans and rested on elastomeric bearings. The beams were tied together and into the existing beams using identical concrete diaphragms and topped with a new deck of same thickness. The deck would be fixed onto the existing deck's steel with additional dowels at $1 \mathrm{~m}$ centres. 


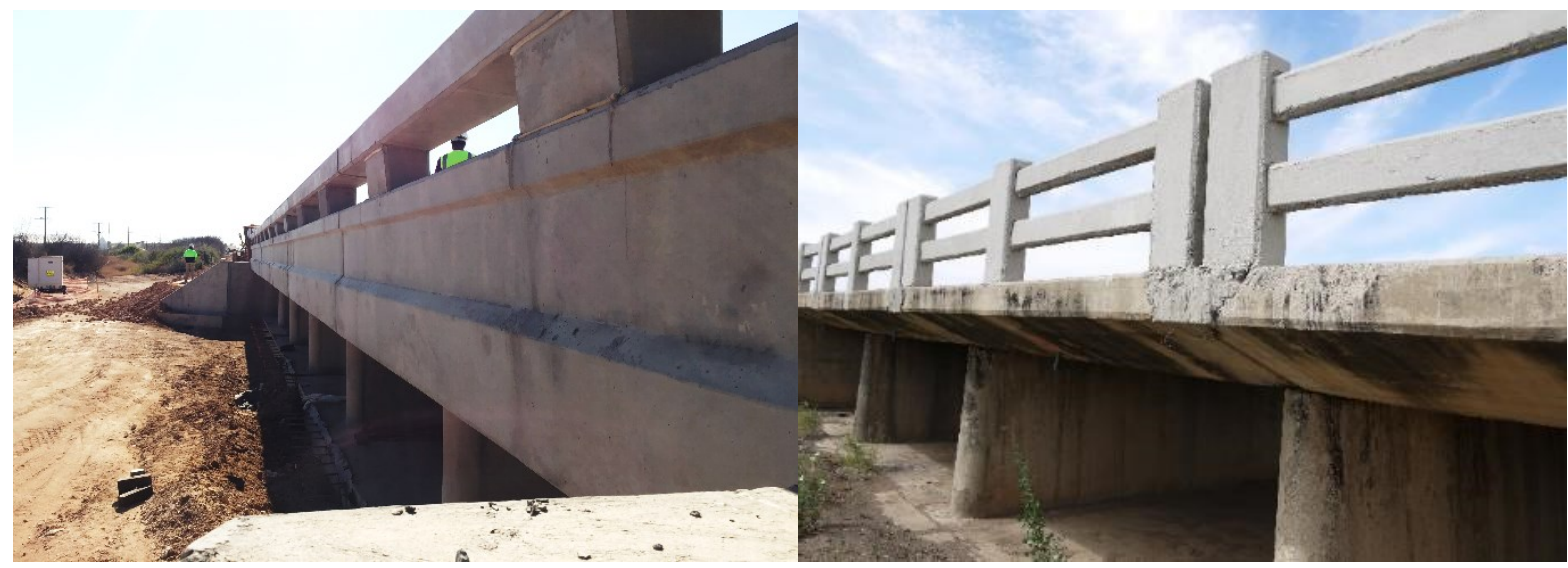

Fig. 10. Comparison of new parapets

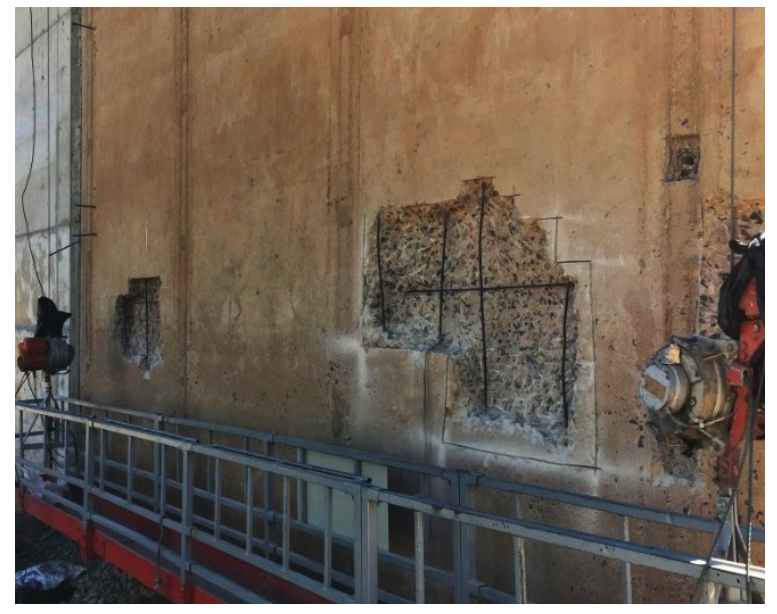

Fig. 11. Steel exposed in pier prepped for repair

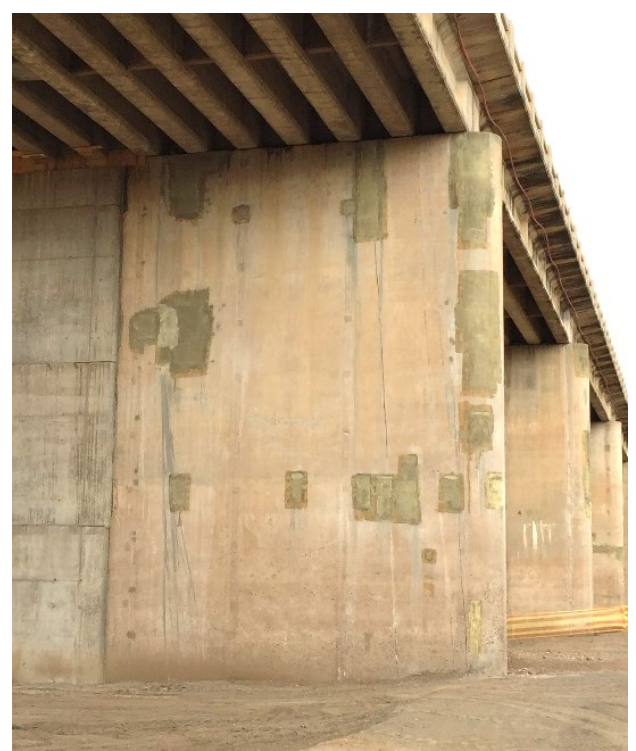

Fig. 12. Repaired surface of pier face

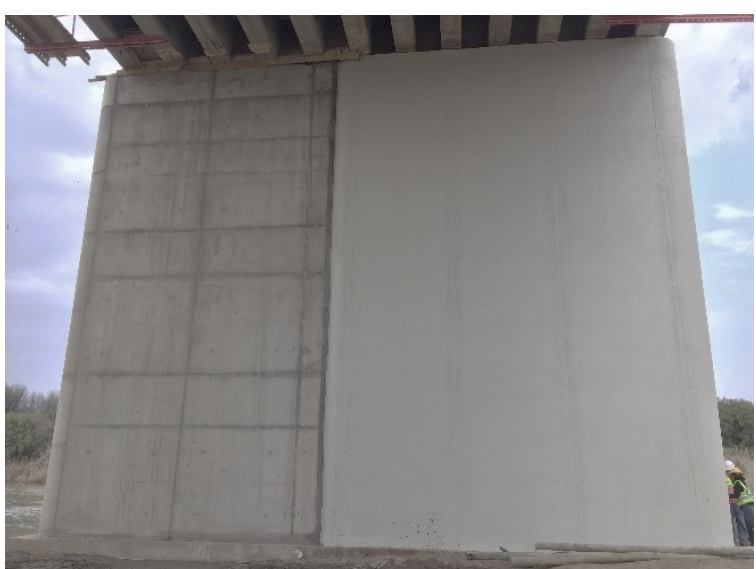

Fig. 13. Final protective coating with new pier section

The abutments, founded on $13,600 \mathrm{~mm}$ diameter piles, were dowelled into the existing abutments and backfilled with over 4000 tons of compacted material up to road level.

A similar approach on B2483 was followed with the various elements. A symmetric extension of the current bridge, the base slab, piers, abutment and deck were all widened out with the same dimensions. The existing approaches to both bridges were reworked and retrofitted with $3 \mathrm{~m}$ apron slabs to improve and match the stiffness of the new widened portion.

The overall scale of the widening operation created a number of challenges pertaining to working at height, placement and handling of beams and traffic management of such an important and high trafficked route. This all required that the utmost care and planning were taken into consideration when completing the widening to mitigate as many risks and affects as possible.

\section{Impact on Environment and Community}

From an economic perspective, the bridge offered a number of significant improvements to the road user and community. 


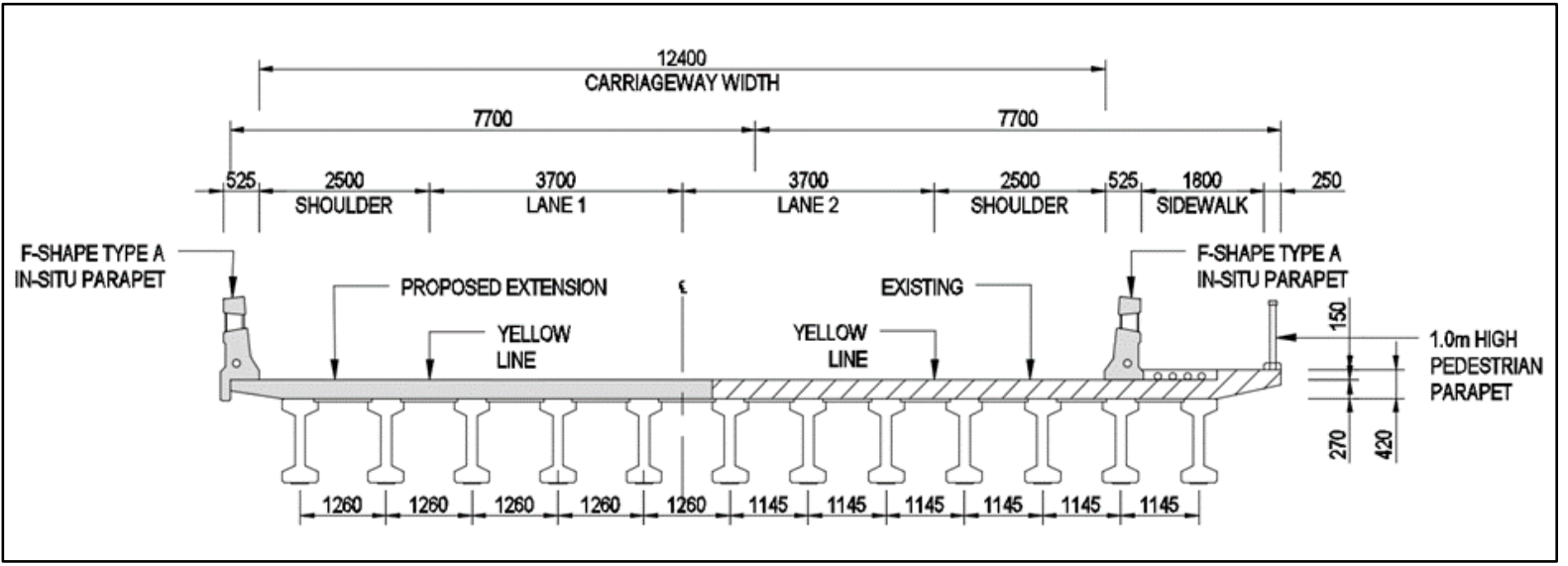

Fig. 14. Proposed widening of existing bridge

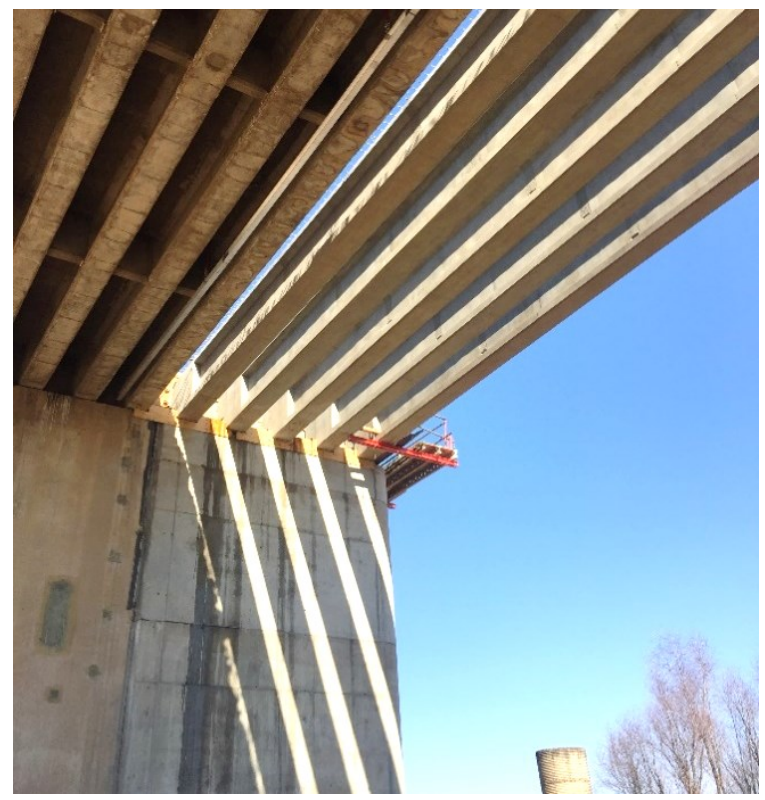

Fig. 15. Beams placed on new piers

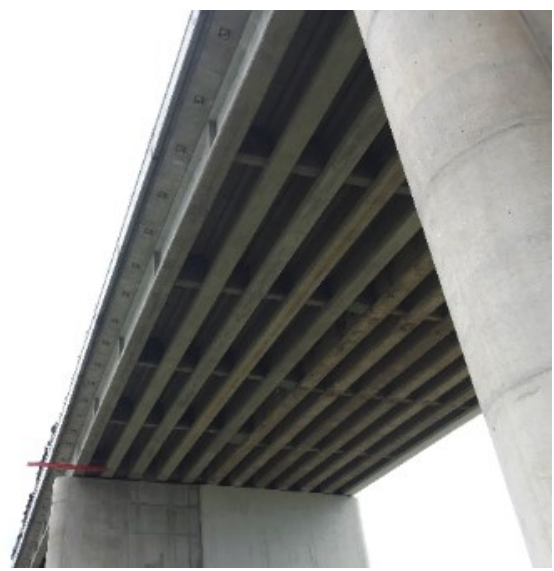

Fig. 16. Final widened section with diaphragms and parapets

Improved traffic flow along with safer conditions and dedicated areas for bicycles and pedestrians have shown to be valuable in ensuring the end user is made to feel safe when using the upgraded section of road. Stronger parapet systems and guardrails with effective emergency areas have created a much better environment that will allow the road to remain an economic bloodline for the region.

Economic stimulants in the form of job creation, education and training, which have been presented simultaneously with the repair and reconstruction, have enabled the community access to the industry. With an overall project value of R100 million, approximately R22 million was focused and directed towards local community small and medium sized enterprises (SMME's).

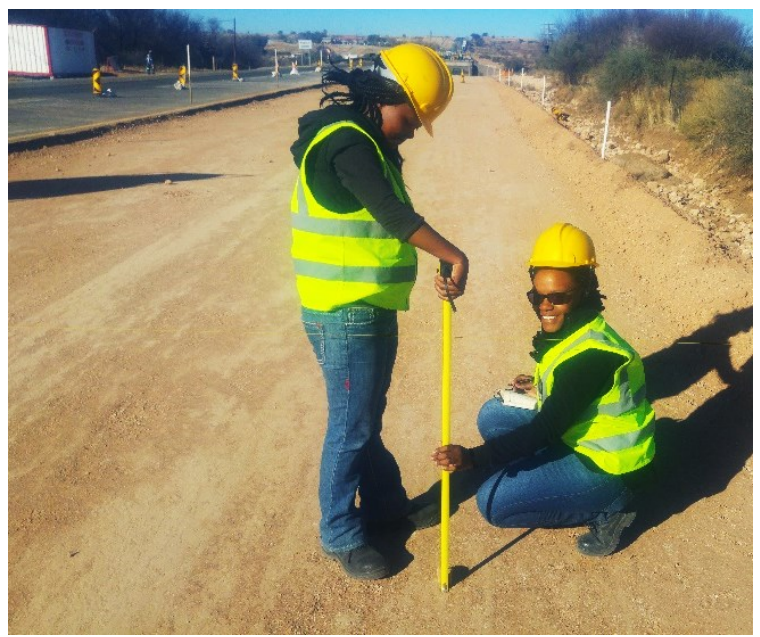

Fig. 17. Students completing onsite training

The multiple endeavours initiated on behalf of SANRAL and their targeted enterprise mandates effectively invigorate the local region and have stimulated the economy. With the completion of the project, the local workforce has been left with the ability to forge fresh opportunities with new skills and experience within multiple facets of concrete and construction work and beyond.

\section{Conclusion}

Management, maintenance and upgrading of the national network of roads and structures is of vital importance; not only to infrastructure development and growth within the 
country, but also within local economic spheres where the creation of opportunities, training and education is felt for many years after the project reaches its completion.

Improving the knowledge and expertise within concrete repair and retrofitting will see that the current network of infrastructure remains a viable and beneficial system for the country as a whole. Done correctly, the continuous, sustainable focus on producing high quality concrete structures and maintaining them will end up yielding a much brighter future for construction in South Africa. 